\title{
THE RESPONSE OF THE LIMPET, PATELLA VULGATA L., TO WATERS OF DIFFERENT SALINITIES
}

\author{
By D. C. ARNOLD \\ Gatty Marine Laboratory, St Andrews
}

(Text-figs. I-5)

During a study of the behaviour of the common British limpet, Patella vulgata L., undertaken in this laboratory, it was found that when dry this species reacts to splashing in a manner which can be correlated with the salinity of the water used. Since no experimental work relating to the chemosensitivity of the limpet could be traced in the available literature, these reactions were further studied in an attempt to identify the receptor regions responsible for detecting variations in salinity. The results so far obtained, while necessarily preliminary in nature, have indicated that in Patella the graded response to different salinities is mediated by receptors in the cephalic tentacles and mantle fringe.

\section{MATERIALS AND METHODS}

The limpets used in these experiments were obtained from bare or weedcovered surfaces at the East Rocks, St Andrews. They were removed by chipping away fragments of the rock on which they were lodged and any animals which appeared to have been damaged in the process were discarded. In the laboratory they were placed in running sea water for some hours, then left dry for about $8 \mathrm{~h}$ before the start of the experiments, most of which were performed during the morning or early afternoon of the day following collection. After use the limpets were kept for a further 3 or 4 weeks under circulation with prolonged periods of dryness each day; they survived well, moving and feeding with every appearance of normality.

On being brought into the laboratory, many of the limpets abandoned the rock to which they were attached and were then placed on the bases of inverted solid watch-glasses, to which the majority readily adhered. Those which did not leave the rock of their own accord were studied without being detached. Stimulation was provided by dropping about $2 \mathrm{ml}$. of water on to the apex of the shell, a small amount passing beneath the shell and affecting the animal. The response, a vertical movement of the front edge of the shell, was recorded by means of a heart lever (arm ratio I2: I). Further details are given in the accounts of the experiments concerned. 


\section{OBSERVATIONS AND EXPERIMENTS}

\section{THE RESPONSE TO SEA AND FRESH WATER}

When dry, Patella remains quiescent, with only occasional slight upward movements of the shell, but, as upon the shore, the animal is not clamped hard down upon its support except when subjected to stimuli of a potentially dangerous nature. In this quiescent state the head is almost completely withdrawn into the mantle cavity, the foot spread over most of the surface beneath the shell and the fringe of the mantle extended almost, but not quite, as far as the edge of the shell (Fig. I $a$ ).

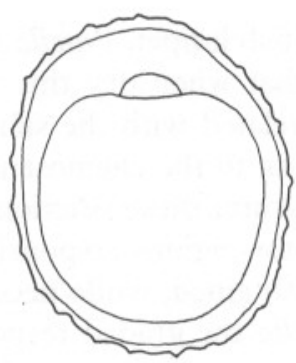

A

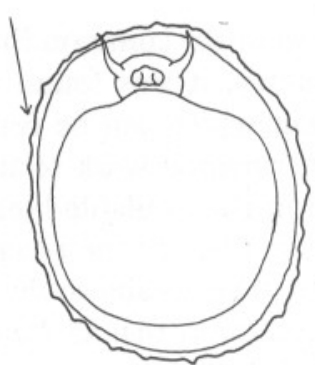

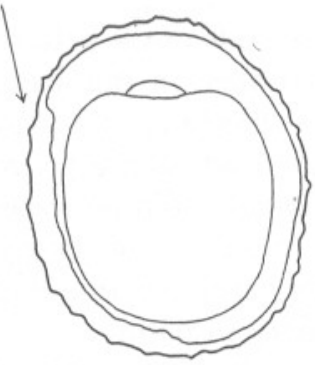

C

Fig. I. The response of Patella to stimulation by sea and fresh water. A, ventral view of quiescent animal, drawn through glass; B, the same animal, after stimulation with sea water; $\mathrm{c}$, the same animal after stimulation with fresh water. Arrows show direction of flow of water.

If a limpet in this condition was splashed with sea water, it responded by lifting the front edge of the shell, advancing the head and extending the cephalic tentacles up to or beyond the edge of the shell (positive response, Fig. $\mathrm{I} b$ ). The vertical movement of the shell was often considerable, being as much as $5 \mathrm{~mm}$ in a high-tide limpet of $50 \mathrm{~mm}$ length. The time elapsing between the stimulus and the commencement of the response varied from less than $30 \mathrm{sec}$ to about $2 \mathrm{~min}$. The response to a single stimulus was normally followed by a sharp contraction of the muscles and a return to the quiescent state. Under repeated stimulation the majority of limpets began to wander and once this had commenced would no longer give clear responses to splashing with sea water. The few animals encountered which gave no response to sea water were later found to have been damaged during or subsequent to collection.

Stimulation by splashing with fresh water elicited the opposite response. As the water flowed beneath the edge of the shell the mantle fringe contracted before it (Fig. Ic), the head was withdrawn even further into the mantle cavity than when the limpet was quiescent and the shell was clamped hard down to exclude the noxious liquid (negative response). Similar stimulation 
of limpets extended in response to sea water resulted in an immediate contraction, begun as soon as the water touched the body and completed in less than $30 \mathrm{sec}$. No animal failed to respond to fresh water in this manner.

\section{SENSORY REGIONS RESPONSIBLE FOR THE REACTION}

An inverted limpet will extend fully in an attempt to right itself, even if it is out of water at the time. This enables the body to be explored for the localization of sensory regions. Exploration by touch revealed five regions characterized by different local reactions to slight contact (Fig. 2). The sole of the foot (I) contracted at the point touched, leaving a deep pit. A similar light touch at the side of the foot (2) induced an outward movement which would

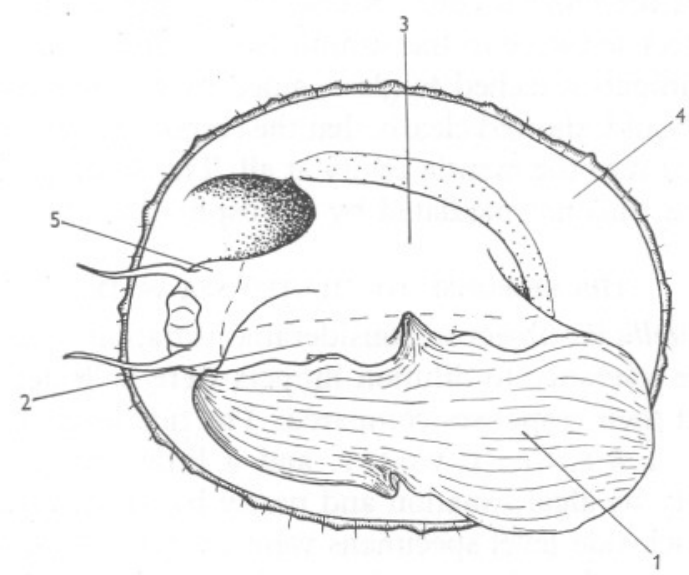

Fig. 2. Ventro-lateral view of extended limpet, showing major sensory regions. For explanation, see text.

ultimately bring the sole of the foot over the object touched. The body and the walls of the mantle cavity (3) were almost insensitive to touch, but the mantle fringe (4) and its tentacles were extremely sensitive and reacted to the slightest contact by immediate withdrawal. The head and cephalic tentacles (5) also recoiled sharply from contact with any object unfamiliar to the animal.

A similar exploration was conducted by dropping water from a fine pipette on to these various regions. When sea water was used on a well-extended limpet regions I-4 gave no recognizable local response, nor did the behaviour of the animal change. The cephalic tentacles, however, would explore the surface of the pipette, if this could be reached, withdrawing only when the pipette ran dry. The foot and general body surface proved equally insensitive to contact with fresh water, but both the mantle fringe and the cephalic tentacles contracted sharply when stimulated in this manner.

While an inverted limpet is endeavouring to right itself it is easy to remove almost all the sea water from the mantle cavity without affecting the activity 
of the animal. Fresh water dropped into the drained cavity was found not to elicit a response, provided that neither the mantle fringe nor the cephalic tentacles were touched in the process. Only when the cavity had been completely filled with fresh water did the activity of the limpet slow and the head withdraw into the cavity. This contraction did not have the appearance of a response to stimulation, but seemed rather a general 'malaise'.

The osphradia, for which both chemoreceptive and tactile functions have been proposed (Hulbert \& Yonge, I937), merited special attention, but, owing to their position far back in the floor of the mantle cavity, could not be removed from intact limpets, while shell-less animals, though they lived, remained inactive. Attempts to destroy the osphradia by cautery were also unsuccessful and therefore it could not be determined directly whether these organs were in fact sensitive to the stimuli used. However, close observation from below of limpets attached to glass, aided by the addition of carmine to the stimulating liquid, showed clearly that the responses were obtained without the entry of water into the mantle cavity at all. The response of Patella to sea and fresh water is thus not mediated by the osphradia.

\section{THE RESPONSE TO DILUTED SEA WATER}

On the shore Patella is subject to considerable variation of salinity. In order to determine the tolerance to dilution limpets were collected from six levels on the shore and their responses compared. The tide levels used (H.W.O.N.T., H.W.E.N.T., M.T., L.W.E.N.T., L.W.O.N.T. and a little above L.W.O.S.T.) were determined partly by algal zonation and partly by direct observation during collection. At each tide level specimens were chosen within two size ranges, c. 25 and c. $45 \mathrm{~mm}$. length, in order to determine whether or not there was a difference in response ascribable to age. In fact, no difference was found.

Each animal was tested with a range of salinities produced by diluting sea water in $10 \%$ steps with fresh water. As 'fresh' water, rain, tap and distilled water were used, but in parallel experiments gave similar results. Stimuli were given at approximately $5 \mathrm{~min}$ intervals and were at random, with the exception that the same stimulus was not given twice in succession. After each stimulus the limpet was washed briefly with fresh water. If a response was given its magnitude was determined by measuring the height of the trace in respect to a superimposed base-line determined from the positions of maximum contraction at the beginning and end of the experiment. Animals on glass frequently moved slightly during the course of an experiment, and when wandering took place to any great extent that sequence of observations was rejected. If no positive response was given the stimulus was marked as 0 , irrespective of whether the limpet did or did not contract to the maximum extent.

All limpets tested were tolerant to some at least of the dilutions, and the 
magnitude of their responses was found to correspond in fair degree with the salinity used. The responses of a given animal to similar stimuli were quite consistent (Table I), though there was a tendency to greater variability as the salinity decreased. The largest responses were invariably given to undiluted sea water, but in several animals the size of the response did not fall off regularly with dilution, but showed an additional secondary peak. The reason for this is unknown. Comparison of limpets taken from different tide levels showed that while there was individual variation within each group, especially

TABLE 1. VERTICAL MOVEMENT IN MM OF THE FRONT EDGE OF THE SHELL OF TWO LIMPETS FROM DIFFERENT TIDE LEVELS IN RESPONSE TO SPLASHING WITH NORMAL AND DILUTED SEA WATER

\begin{tabular}{|c|c|c|c|c|c|c|c|c|}
\hline \multirow{2}{*}{$\begin{array}{l}\text { Tide } \\
\text { level }\end{array}$} & \multirow{2}{*}{$\begin{array}{l}\text { Length } \\
\text { of shell } \\
(\mathrm{mm})\end{array}$} & \multicolumn{7}{|c|}{ Relative salinity of sea water } \\
\hline & & $100 \%$ & $90 \%$ & $80 \%$ & $70 \%$ & $60 \%$ & $50 \%$ & $40 \%$ \\
\hline \multirow[t]{5}{*}{ H.W.O.N.T. } & 26 & $2 \cdot 00$ & I.33 & $I \cdot 25$ & 0.83 & 0.58 & 0.25 & o \\
\hline & & $2 \cdot 00$ & $1 \cdot 58$ & $\mathrm{I} \cdot \mathrm{I} 7$ & 0.75 & 0.50 & 0.17 & 0 \\
\hline & & $\mathrm{I} \cdot 9 \mathrm{I}$ & $\mathrm{I} \cdot 75$ & $I \cdot 42$ & $I \cdot 25$ & $\mathrm{I} \cdot 25$ & 0.42 & 0 \\
\hline & & 2.09 & - & - & - & - & - & 一 \\
\hline & Mean & $2 \cdot 00$ & $\mathrm{I} \cdot 55$ & $I \cdot 28$ & 0.94 & 0.78 & 0.28 & 0 \\
\hline \multirow[t]{4}{*}{ L.W.E.N.T. } & 24 & $\mathrm{I} \cdot 75$ & $I \cdot 42$ & $I \cdot I 7$ & $\mathrm{I} \cdot 50$ & 0.92 & 0.25 & - \\
\hline & & $2 \cdot 00$ & $\mathrm{I} \cdot 25$ & $\mathrm{I} \cdot 08$ & $I \cdot 42$ & $\mathrm{I} \cdot \mathrm{I} 7$ & 0 & - \\
\hline & & $\mathrm{I} \cdot 75$ & $\mathrm{I} \cdot 58$ & I. 42 & $I \cdot 42$ & 0.75 & 0 & - \\
\hline & Mean & $\mathrm{I} \cdot 83$ & $\mathrm{I} \cdot 42$ & $I \cdot 22$ & I. 45 & 0.95 & 0.08 & - \\
\hline
\end{tabular}

obvious in those from the mid-tide region, several distinct trends could easily be recognized when passing from the upper to the lower tide limits. Limpets taken from H.W.O.N.T. (the upper limit of colonization) gave very consistent and clear-cut responses and were tolerant to salinities below 50\% sea water (Fig. 3) and in one case even as low as $20 \%$. Their movements were quick to commence, large and smooth. In contrast, limpets collected a little above L.W.O.S.T. (the lower limit of colonization) were negative to salinities of $80 \%$ sea water or less and gave much smaller and more irregular responses than did high-tide animals of similar size. These extremes were linked by the range of behaviour of animals drawn from intervening tide levels (Fig. 4).

\section{THE RESPONSE TO SOLUTIONS OF SODIUM CHLORIDE}

Some limpets from H.W.O.N.T. were tested with solutions of sodium chloride. This was of Analar grade made up in distilled water in concentrations ranging from $100 \mathrm{~g} / 1$. down to $20 \mathrm{~g} / 1$. The responses given to these solutions resembled those given to natural and diluted sea water, except that the movements were more jerky and less rapid, while the limpets soon became refractory. Consistent results could only be obtained by allowing the animals frequent and lengthy periods for recovery during the course of each experiment.

Responses to undiluted sea water and to a sodium chloride solution of equivalent salinity were of similar magnitude, while abnormally large responses 


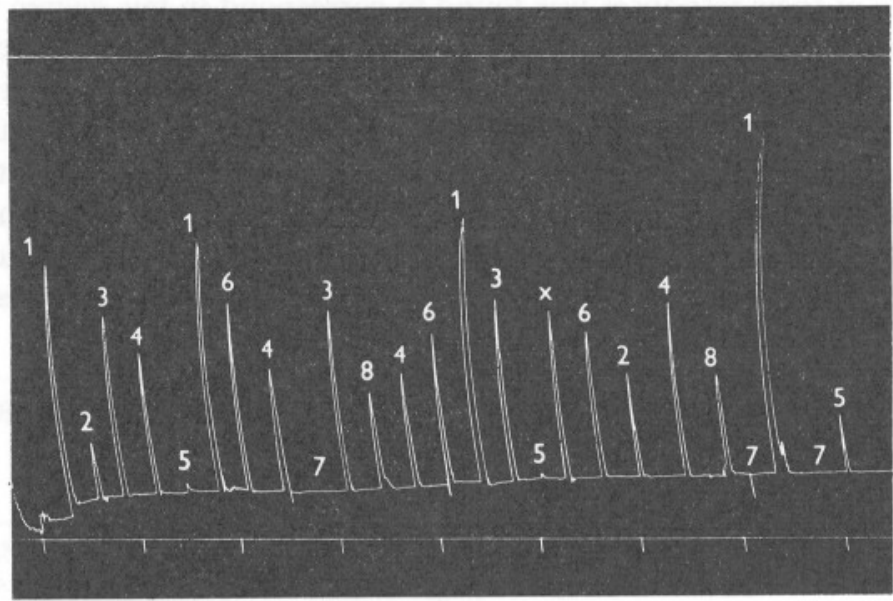

Fig. 3. Response of limpet, taken from H.w.o.N.T., $46 \mathrm{~mm}$ long, to normal and diluted sea water. Time at $15 \mathrm{~min}$ intervals. Key to numbering: $\mathrm{I}=$ normal sea water; $2=60 \%$ sea water; $3=90 \%$ sea water; $4=70 \%$ sea water; $5=40 \%$ sea water; $6=80 \%$ sea water; $7=30 \%$ sea water; $8=50 \%$ sea water. $\times=$ spontaneous movement.

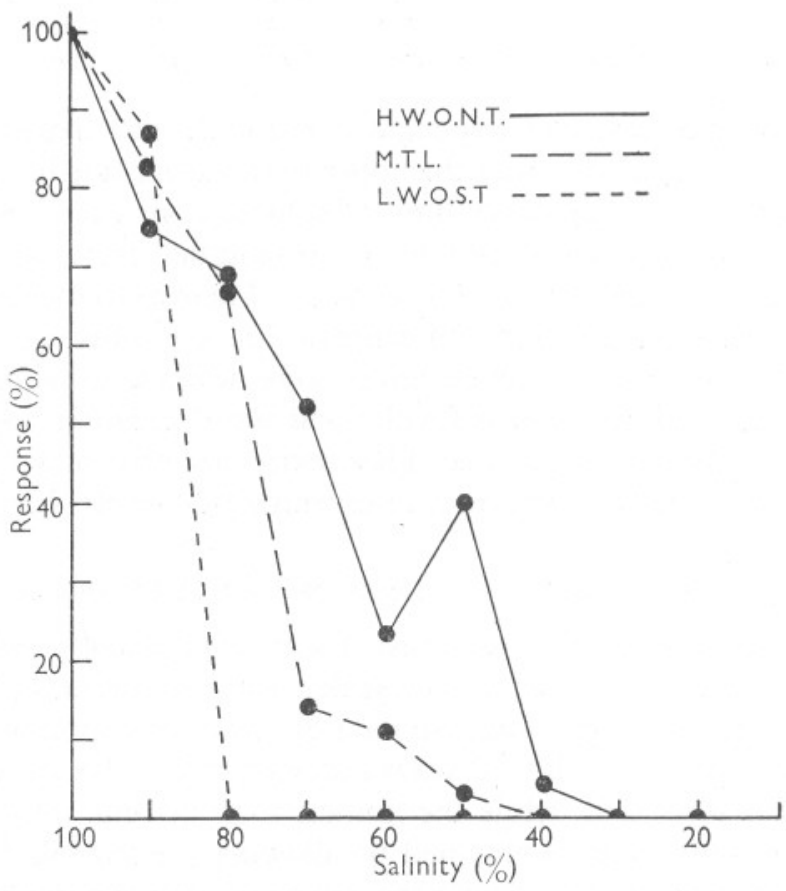

Fig. 4. The response of limpets from different tide levels to various salinities. Salinities expressed as percentages of undiluted sea water, responses as percentages of response to undiluted sea water. 
were given to solutions containing $40 \mathrm{~g} / \mathrm{l}$. $\mathrm{NaCl}$ (Fig. 5). Above this concentration the responses once more diminished in size.

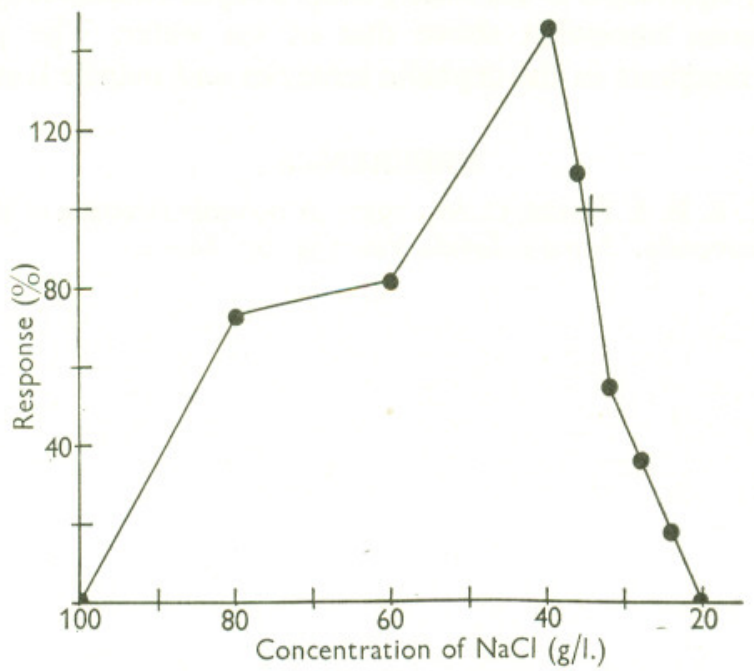

Fig. 5. The response of a limpet from H.w.o.N.T. to various $\mathrm{NaCl}$ concentrations. Concentrations expressed as $\mathrm{g} \mathrm{NaCl} / 1$, , responses as percentages of response to undiluted sea water (salinity c. $34.5 \%$ ), the position of which is shown by a cross.

\section{DISCUSSION}

These experiments have yielded the results which are to be expected on a priori considerations. The negative response of Patella to water of low salinity, the increasing tolerance as one ascends the shore and the more immediate and larger responses to splash shown by the high-tide limpets, are all characters which are to be expected as adaptations to a progressively more rigorous environment in which activity is curtailed by ever longer periods of dryness. Whether these potentialities are possessed by all limpets and expressed according to their position on the shore, or whether the possession of certain powers of activity under adverse conditions determines the position ultimately occupied by the adult limpet is not known.

The perception of salinity by the mantle fringe and cephalic tentacles is also to be expected, since these are the parts of the animal which are most exposed to the environment.

\section{SUMMARY}

Patella vulgata gives a positive response to splashing with sea water or water of high salinity, and a negative response to fresh water or water of low salinity. The intensity of the positive response broadly corresponds with the salinity of the water used. There is a greater response to splash and a greater tolerance 
to reduced salinity in limpets from high-tide than in those from low-tide regions. A positive response is given to $\mathrm{NaCl}$ solutions of concentrations approximately equivalent to sea water, while a supra-normal response is given to concentrations somewhat above that of sea water. The perception of salinity is by receptors in the cephalic tentacles and mantle fringe.

\section{REFERENCE}

Hulbert, G. C. E. B. \& Yonge, C. M., I937. A possible function of the osphradium in the Gastropoda. Nature, Lond., Vol. 139, pp. 840-1. 